\title{
The care offered by nurses to elders with coronary artery disease from the perspective of Transitions Theory
}

\author{
Cuidado de enfermeiras a idosos com doença arterial coronariana na perspectiva da Teoria das Transições \\ Cuidado de enfermeras a ancianos con enfermedad arterial coronaria en la perspectiva de la Teoría de las Transiciones
}

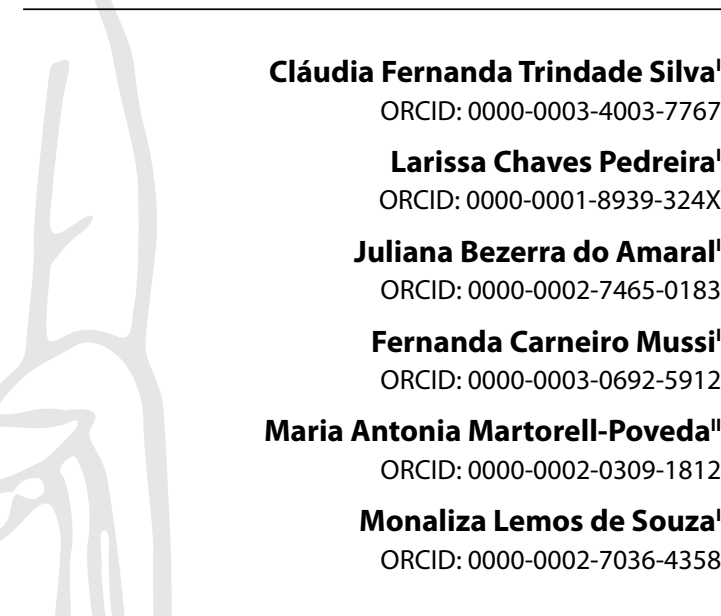

'Universidade Federal da Bahia. Salvador, Bahia, Brazil. "Rovira i Virgili University. Tarragona, Catalunya, Spain.

How to cite this article: Silva CFT, Pedreira LC, Amaral JB, Mussi FC, Martorell-PovedaMA, Souza ML. The care offered by nurses to elders with coronary artery disease

from the perspective of Transitions Theory. Rev Bras Enferm. 2021;74(Suppl 2):e20200992. https://doi.org/10.1590/0034-7167-2020-0992

Corresponding author:

Cláudia Fernanda Trindade Silva E-mail: claudiafernanda.trindade@gmail.com

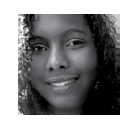

EDITOR IN CHIEF: Antonio José de Almeida Filho ASSOCIATE EDITOR: Hugo Fernandes

Submission: 09-26-2020

Approval: 01-26-2021

\section{ABSTRACT}

Objective: To analyze the planning and implementation of the care offered by nurses to elders with coronary disease during the hospital-house transition. Methods: Qualitative research that used the Transitions Theory as a theoretical reference. The participants were 12 nurses who work in a hospital that specializes in cardiology, in the city of Salvador-BA. A semistructured interview was carried out from January to February 2018, and the data was analyzed using the Content Analysis technique. Results: Transition care takes place on the day of discharge. The presence of the family was found to be a facilitator; low adherence, poor financial situations, the low educational levels inhibited its implementation. The rehospitalization is an indicator of the results of the transition of care. Final considerations: The planning and implementation of transition care is not effective. It must provide safety in the management of self-care in the home of elders with coronary disease and their families. Descriptors: Transitional Care; Aged; Nursing; Coronary Artery Disease; Care, Patient Focused.

\section{RESUMO}

Objetivo: Analisar o planejamento e implementação do cuidado de transição hospital-domicílio de enfermeiras à pessoa idosa com doença arterial coronariana. Métodos: Pesquisa qualitativa que utilizou como referencial teórico a Teoria das Transições. Participaram 12 enfermeiras atuantes em um hospital-referência em cardiologia da cidade de Salvador-BA. Realizou-se entrevista semiestruturada entre os meses de janeiro e fevereiro de 2018; e analisaram-se os dados pela técnica de Análise de Conteúdo. Resultados: $O$ cuidado de transição é efetuado no dia da alta. A presença do familiar foi considerada facilitadora; e a baixa adesão, condição financeira e nível de escolaridade foram apontados como inibidores da sua implementação. A reinternação é o indicador de resultado do cuidado de transição. Considerações finais: $O$ cuidado de transição é planejado e implementado de maneira ineficaz. É necessário que ele proporcione segurança na gestão do autocuidado em domicílio do idoso com doença coronariana e de sua família. Descritores: Cuidado de Transição; Idoso; Enfermagem; Doença Arterial Coronariana; Assistência Centrada no Paciente.

\section{RESUMEN}

Objetivo: Analizar el planeamiento e implementación del cuidado de transición hospitaldomicilio de enfermeras a ancianos con enfermedad arterial coronaria. Métodos: Investigación cualitativa que utilizó como referencial teórico la Teoría de las Transiciones. Participaron 12 enfermeras actuantes en un hospital-referencia en cardiología de Salvador-BA. Realizó entrevista semiestructurada entre los meses de enero y febrero de 2018; y analizaron los datos por la técnica de Análisis de Contenido. Resultados: El cuidado de transición es efectuado en el día de la alta. La presencia del familiar fue considerada facilitadora; y la baja adhesión, condición financiera y nivel de escolaridad fueron apuntados como inhibidores de su implementación. La reinternación es el indicador de resultado del cuidado de transición. Consideraciones finales: El cuidado de transición es planeado e implementado de manera ineficaz. Es necesario que él proporcione seguridad en la gestión del autocuidado en domicilio del anciano con enfermedad coronaria y de su familia.

Descriptores: Cuidado de Transición; Anciano; Enfermería; Enfermedad Arterial Coronaria; Asistencia Centrada en el Paciente. 


\section{INTRODUCTION}

Transitional care is defined as that the care provided for the transition of an individual from one mode of care to another. The context between hospital and house means that the responsibility of caring for the patient is transferred from the health professionals to the user, the user's family, and/or other caregivers. When effective, the transition leads to a better adherence to treatment, and to a lower proportion of mistakes or adverse reactions, reflecting the reduction of hospital readmission rates ${ }^{(1-2)}$.

The term "transition" started to be used in the 1960s due to the Transitions Theory, a middle-range theory proposed by the Egyptian-American nurse Afaf Ibrahim Meleis. To her, transition is the change between different environments, conditions, or stable states, demanding knowledge from the individual and willingness for internal and external adaptations with regard to the emergent paradigm $^{(3)}$. These situations are not always desired, transcending the control of the person as in situations that involve death and disease, and can lead to dangerous or noneffective transitions, characterized by instability, vulnerability, stress, insecurity, and even by ruptures in the cycle of life ${ }^{(4)}$. Therefore, interventions from health professionals are necessary to aid in the difficulties found in transpositions, to minimize or avoid risks to the physical and mental health of the person affected, and also to that of their relatives and caregivers.

For the elders affected by the coronary artery disease (CAD), transition care is essential, since they must incorporate or change life habits, which requires adapting to new eating habits, medication use, to the practice of physical activity and to potential fragilities or limitations that can come after hospitalization, which, often, is long.

In elders, the chronic nature of CAD, coupled with other comorbidities, changes due to senescence and the fragility of the patients, increased the number of hospitalizations, meaning it can bring complications during the hospital treatment and after discharge ${ }^{(5)}$. In Brazil, in 2019, 80 thousand elders were hospitalized due to acute myocardial infarctions, and 49 thousand adults from 20 to 59 years old were hospitalized for the same reason. The hospitalization time of elders was almost twice as long as that of adults, in the same period ${ }^{(6)}$. These broad strokes make explicit the importance of the transition care to strengthen the self-care capacity of this age group.

The changes in the lifestyle that the elders must make to treat CAD can be embraced when the elders are motivated by the desire to adopt healthier life habits ${ }^{(7)}$, or neglected, when they are imposed by the health professionals, or when the patients, relatives and caregivers are not adequately trained to guide themselves with regard to the care recommended; not to mention, they can also be ejected when there is no personal will(8).

The Transitions Theory states that nurses must be attentive to the form in which the elder reacts to a situation of hospitalhouse transitions, identifying the factors involved (environment, socioeconomic condition, family support, and personal will) to subsidize the elaboration of strategies shared with the elder, its relatives/caregivers and health networks available that can facilitate the interaction and the confrontation of the changes needed to control the disease, such as the best way to adapt for the treatment in general ${ }^{(3)}$.
As a result, the nurses have a fundamental role in the transition, since they remained really close to the elders and their relatives/ caregivers, providing direct care for the attention to their health needs. Furthermore, they have the competence and skills to plan and implement transition care in an effective and individualized way, and one of the main pillars is health education ${ }^{(9)}$. Some care models that nurses implement and manage for elders with chronic diseases have positive results that are well documented as the models Interventions to Reduce Acute Care Transfers (INTERACT); Missouri Quality Initiative (MOQI); Transitional Care Model (TCM) ${ }^{(10)}$.

Getting to know how this practice has been taking place and how its possible weaknesses and strengths have been formed makes it possible to elaborate effective intervention with transition models and effective care. From this context, this study emerged from the question: How do nurses plan and implement the transition care for elders with CAD?

\section{OBJECTIVE}

To analyze the planning and implementation of the care offered by nurses to elders with coronary disease during the hospital-house transition.

\section{METHODS}

\section{Ethical aspects}

This research is part of the master's degree dissertation called "Nursing care in the hospital-home transition of elders with coronary artery disease ", developed in the Post-Graduation Program of the Nursing School of the Universidade Federal da Bahia (EEUFBA). It was approved by the Research Ethics Committee of the hospital where it was carried out, and it respected the ethical precepts related to researches with human beings, as determined by Resolution 466/12 from December 12, 2012, from the National Council of Health ${ }^{(11)}$.

All nurses who participated agreed and signed the Free and Informed Consent Form, becoming aware of the potential risks and benefits, as well as of the possibilities of refusal or withdrawal in any stage of the research, with no repercussions.

To guarantee anonymity, the participants of the research will be presented in the Results using alpha-numerical codes, represented by the letter "E" (for the nurses), followed by a number in accordance with the order in which the interview was carried out.

\section{Theoretical-methodological framework}

This study used as a methodological framework the qualitative research, guided by the theoretical framework of the Transitions Theory, which is based on three main constructs that guide nursing therapeutic interventions. The first, called "Nature of transition", is related to the classifications, to standards of occurrence, and to their properties. The second construct, called "Transition conditions" refers to the factors that facilitate or inhibit the transition process of the individual, be them internal or external. And the third is related to the "Patterns of response" of the individual in the transition, which are a way to evaluate nursing therapeutic interventions ${ }^{(3)}$ 
The diagram of the Transitions Theory ${ }^{(3)}$ can be seen in Image 1. This theory was used as a theoretical base for this work because it is widely applied in nursing practice and is adopted as a theoretical base of care in the transition of many groups, such as elders, people with psychiatric disease, caregivers, women, parturient or not, and patients with chronic diseases ${ }^{(4)}$.

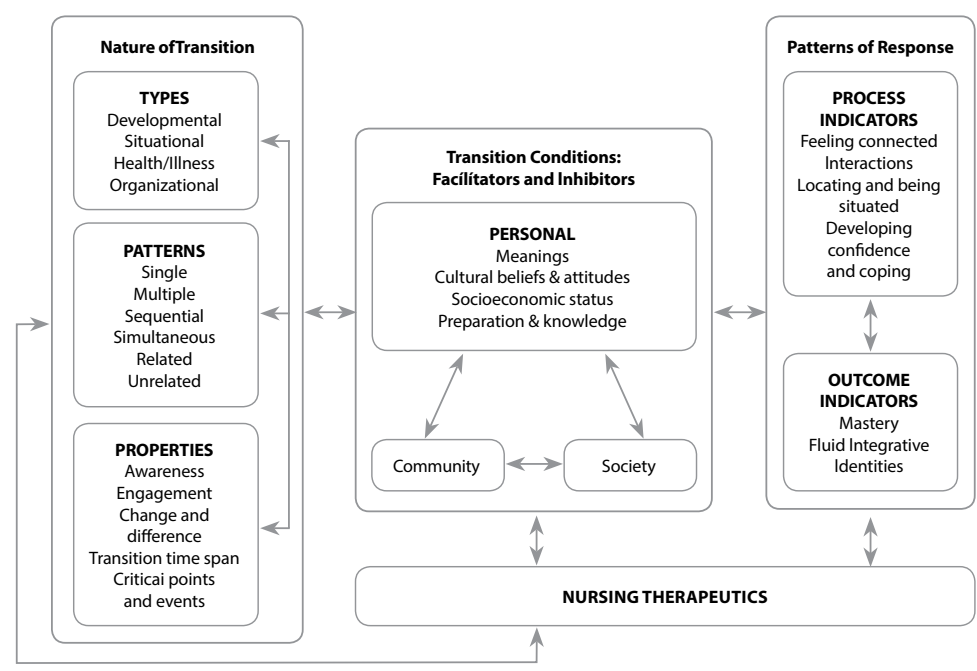

Source: Meleis $A)^{(3)}$

Figure 1 - Diagram of Meleis's Transitions Theory: a middle-range theory

\section{Type of study}

Qualitative, descriptive, and exploratory research, guided by the tool COREQ ${ }^{(12)}$. The qualitative research was chosen due to the desire to understand, through the statements of the participants, how do nurses plan and carry out care during the hospital-home transition in their practice.

\section{Methodological procedures}

\section{Study Setting}

The study was carried out in a large-size hospital, in the city of Salvador, Bahia, Brazil. The hospital is specialized in attending people with cardiological diseases of many levels of complexity, both from the Single Health System and in the complementary health system. The interviews were carried out with nurses that work in the Cardiac Hospitalization Unit (UIC) and in the SemiIntensive Cardiovascular Unit (UCSI).

The UIC is a hospital unit destined to the attention of adults with non-critical cardiopathies. Its users and their relatives are prepared for the hospital discharge. The UCSI, on the other hand, aims at attending people with coronary artery disease who need their health state monitored more closely, but are not in a critical state. This unit was chosen as the research location because, after the situation of the patient improved, the users could be sent to the UIC or receive hospital discharges directly from the unit, making it an environment where hospital-home transitional care can take place.

The Intensive Care Units that care for people with CAD were excluded, since the patients in these environments are in a worsened state, including the limitation of visits, which hinders an effective transition of care.

\section{Data sources}

The participants were 12 nurses which were in accordance with the following inclusion criteria: working in one of the units chosen for the research and working in the direct assistance to elders with CAD. Four nurses were excluded, who worked at UIC on occasion, according to the demand, but were not stationed in the sector. As a result, four nurses from UIC and eight from UCSI were interviewed. That meant that all nurses from the latter participated in the study.

\section{Collection and organization of data}

Data collection happened between January and February 2018. Potential participants were identified using the work timetable made available by the nursing management of the institution. Later, the researchers got in touch for the first time with them at their work units, to present the research and the Free and Informed Consent Form and to schedule the interviews to a day and time convenient to the participants. There were no refusals.

The interviews took place within the hospital. They were interactive, face to face, in a private location, to facilitate interaction between the participant and the researcher. They were recorded in an MP3 player and transcribed in full.

The script of the semistructured interview was made up by two parts: the first was related to the sociodemographic characteristics, education, and to the place where the participants worked. The second had open questions, targeted at discussing the study's subject. They were: What does transition care mean? What are the facilities and/or difficulties that interfere in the continuity of treatment after hospital discharge and that you identify in elders with CAD? How do you carry out planning and when do you implement the care to be able to discharge the elders hospitalized with CAD, their relatives and/or caregivers? How do you evaluate the response of elders with CAD and their relatives/ caregivers with regard to the care implemented at discharge?

The research instrument was validated using a pre-test, to find whether they were understood by the interviewees. Three pre-tests were carried out with the nurses who worked at the UIC on occasion, and, as a result, were excluded from this study.

\section{Data analysis}

The organization of the material for analyzing the data started immediately after the end of the interviews, using the Content Analysis technique ${ }^{(13-14)}$. Three stages were followed. Stage 1, the pre-analysis, was the interaction of the researcher and the material through skimming, to identify, in their discourses, the answers to the investigation question, which guided to Stage 2 , called "Exploration of the material". In this stage, the text was divided according to similarities and differences, culminating 
on its coding by categories, which were formed respecting the principles of thoroughness, representativity, homogeneity, pertinence, and mutual exclusion. Finally, Stage 3 consisted in the "Proposal of inferences and data interpretation", based on the theoretical framework adopted and on publications about the theme. In all stages, the main constructs of the Transitions Theory were used as reference.

\section{RESULTS}

From the 12 nurses interviewed, 11 were female, and 7 were specialized in the field of cardiology. Their age varied from 28 to 45 years old, and their time acting in the cardiological units varied from 5 days to 14 years.

Through the analysis of the statements, it was found that the transitional care being carried out is based on some elements of the Transitions Theory constructs, which are: nature of transition (identification of critical elements), transition conditions (recognition of factors that facilitate or inhibit the transitional care), and patterns of response to the transition and to the therapeutic nursing intervention. This allowed for the identification of four categories of analysis, which were: Guidance as a nursing therapeutic intervention in the care for the hospital-home transition; Recognition of critical elements for the care for the hospital-home transition; Conditions of the care for the hospital-home transition; Patterns of response to the care for the hospital-home transition.

\section{Category I- Guidance as a nursing therapeutic intervention in the care for the hospital-home transition}

Guidance were the therapeutic intervention used by nurses in the hospital-home transition care. In this regard, transitional care starts after the nurses are informed by the medical team of the discharge, which happens in the day of discharge. At this time, the guidance is provided, in general, a single time. It is done verbally, with the aid of a written instrument, called "Discharge report", which is filled in by the nurse.

[...] unfortunately, this is planned in the day of discharge [...]. At the time the elder is about to leave, I guide them about the type of care, eating habits, wound dressing [...]. I write the information in the nursing report and ask if they have any questions our doubts. (E1)

[...] when the physician determines that the elder will go home, I provide the necessary guidance for home care. This happens in the day of the discharge of the patient. (E4)

At the moment of discharge... from this moment on, I trace the plan, I guide them and deliver the written report. (E6)

At the day of discharge, I offer basic information on the necessary home care. In general, I do not manage to provide a minute explanation of what must be done. (E11)

I wait for the physician to communicate with regard to the discharge, and only then I start the guidance. I deliver the exams, make the wound dressings (when there is) and give the explanations necessary to carry out care at home, or advise them when they must come back to the hospital to do so. (E12)

\section{Category II - Recognition of critical elements for the care for the hospital-home transition}

According to the nurses, situations that can increase the possibility of dangerous transitions - also called, in the Transitions Theory, of "Critical points" - were: the presence of comorbidities, users who had been submitted to more complex procedures (e.g. surgeries of myocardium revascularization) or who needed to use parenteral devices or medications of at home. Considering these situations, the nurses planned and implemented transitional care before the day of discharge.

If the elder uses insulin at the hospital, I start advising during their whole hospitalization. I request nursing technicians to, when administering the medication, guide the patient and the family so, at the moment of hospital discharger, there is not much information. [...] The sooner it starts, the earlier they manage to assimilate and feel safer at the moment of discharge (E3)

I prepare the elder who takes many medications through daily guidance, talking about why it is indicated and why it must be taken at the right times. It is informal, during the practice itself. (E5)

When the elder shows many comorbidities or was submitted to a cardiac surgery, I start guiding them since the first or second hospitalization day, because it is a large surgery and there will certainly be other doubts. If you wait to give all this guidance at the time of discharge, he is likely to leave feeling insecure. (E9)

\section{Category III - Factors that condition the care for the hospital- home transition}

According to the participants, the presence and the involvement of family/caregivers in the hospital environment were factors that facilitated the implementation of transitional care, since they share the information provided at the moment of discharge with the elder, and, in general, continue providing car after hospital discharge.

The following stood out as negative conditioning factors: more severe clinical conditions, degree of dependence, low educational level, and low adherence to the treatment indicated for the elder with CAD.

When the elder has a low educational level, you must call the relative or the person accompanying them. Because they cannot identify the medications they are going to use and depend on the care of another person. (E1)

I always call the family to be present at the moment I will provide the guidance, because the elder has a stubborn trait: even if you tell them 50 times. The presence of the relative is important! (E6)

I believe that the general condition of the elder makes it more difficult to implement transitional care. If they have trouble reading due to visual deficits, they are likely to not understand what is written in the prescription. (E7)

[...] it is difficult when the elder does not adhere to the treatment and to healthy life habits. I try to adapt the guidance, because it is no use establishing conducts that we know the patient will 
not adhere to as well as possible, since this is an elder with their own fragilities. (E8)

If the elder is dependent, you must identify the caretaker responsible, who will administer the medication and encourage them to physical activity. [...] if my plan is different from his routine, he has a tendency not to follow through. (E10)

\section{Category IV - Patterns of response to the care for the hospital-home transition}

The nurses interviewed have no information on the state of health of the elders with CAD after hospital discharge. Therefore, the responses to the transition care implemented are not evaluated. The parameter used to evaluate the effectiveness of transition care is the readmission to the hospital.

I notice that the discharge preparation was effective when the patient takes a long time to be readmitted. (E2)

I cannot get a feedback, because I would need to have some type of control over this patient after discharge, and I do not. [...] when the elder with coronary disease is readmitted, due to not following through with the prescribed medication or to the diet, I can infer that the care did not take root. (E4)

When the patient takes longer to be hospitalized, then I see the care was effective. (E9)

\section{DISCUSSION}

Any change in the health state is an important transition in the life of the individual, specially when he is an elder, who is already living through the alterations provoked by senescence. During a hospitalization, the care in the transition to the home must start as soon as possible, an must be included in the process of nursing care, seeking to provide a good understanding about self-care, to value the adherence to the treatment, and to provide support to the change of life habits ${ }^{(15-16)}$ that increase the risk for $\mathrm{CAD}$. For that, one must consider the individuality and the socioeconomic and cultural context of each person, the perspective and the conditions that it has for one's own care, their plans for life and sources of pleasure, offering safety to continue care and treatment out of the hospital environment.

To this end, nurses have an essential support role. Their intervention must be based on the history of the individual; on the analysis of their response considering the situation experienced, as is the case of their degree of acceptance and willingness to change; in the identification of positive and negative factors that stem from this process; from the evaluation of the actions implemented, considering the response of the patient when confronted with the transition ${ }^{(15)}$.

Therefore, this process must be individualized, taking into consideration the cognitive level, the intellectual development, the educational level, and the life experiences of the elder, aiming to encourage them to change their own reality due to the changes provoked by the disease ${ }^{(17)}$.

For the elder with $C A D$, effective transition care is necessary due to the specificities of the disease and to the necessary changes that will be experienced. Preparing for changes in one's life habits, which includes doing physical exercise, choosing healthy eating habits, and using the medication correctly, are determinant factors to reduce the risk factors of CAD and, in turn, to guarantee the success in the treatment of the disease and in the prevention of new ischemic events ${ }^{(8)}$.

However, the study at hand made evident that there is no previous and continued planning for the information that should be shared with the patient and relatives/caregivers. The guidance that aim to prepare for discharge are usually carried out at the day of patient discharge, meaning the patient and their relatives/caregivers have a poor understanding due to the excessive amount of information transmitted, information which is often distant from their social and cultural contexts, their life projects, and the perspectives they have for their self-care.

The nurses notice that the patients must change their habits, but the guidance is normative and prescriptive. Transition care must be implemented as early as possible in the hospital environment, so the nurses get to know the needs of the patients, to better adapt for post-discharge habits.

The preparation for home care that is done close to the moment of discharge of the elders can increase the risk that they will not be able to reach the goals they need, due to the lack of clarity and understanding of information and/or training, especially on the part of those with more complex health needs ${ }^{(16)}$.

However, it could be noticed that, when there were critical points, the nurses interviewed started their guidance earlier, since they believed that the excessive information at the day of discharge could hinder home care. Therefore, it can be noticed that the identification of these risk situations was important for them to manage the transition process in this period in which the individual was more vulnerable.

The critical points identified by the nurses included situations that demand more guidance, requiring from the family/caregivers attention and preparation, more ability and involvement. This includes care for the operating wound of patients who underwent myocardium revascularization surgery, or to the use of parenteral medication (insulin and anticoagulants), as well as the use of enteral or bladder tubes.

However, this conduct should be offered to all patients, formally, throughout the institution, despite the presence of any critical event. The planning and the implementation of transition care is a complex part of nursing acre, which means that it should be carried out as early as possible, according to the five stages of the nursing process (investigation, diagnosis, planning, implementation, and evaluation), all of which must be adequately documented to facilitate the communication between teams and the monitoring of the health state of the elder with $C A D^{(17)}$.

Regarding the ease of implementation of transition are, the nurses stated that relatives/caregivers contribute positively for the process. Their presence is seen as an important link for the information offered to become rooted, guaranteeing the continuity of home care.

The involvement of the relative/caregiver is essential in the maintenance of the wellbeing and of the quality of life of the elder during the continuity of care, when confronted with potential fragilities or with the inability for self care after hospital 
discharge ${ }^{(17)}$. Therefore, their participation in the entire process of implementing transition care leads to a better preparation for home care, especially when the elder depends on them ${ }^{(18)}$.

However, the transfer from the care of trained professionals to that of relatives/caregivers responsible for the elder with CAD in the home can be a stressing moment when the necessary support is not provided by an effective communication between health professionals, patients, and relatives/caregivers ${ }^{(1)}$. There is an attempt to establish a relationship of partnership with the latter, to involve them effectively in the role of support for the elder.

A study carried out with 13 elders and 9 caregivers hospitalized in 2 hospitals in the United States, showed important shortcomings in the communication between health professionals, elders, and relatives. In general, the relatives had no knowledge about the plan of treatment transition; and when they received this knowledge, the information came in a normative way, leading to insecurity and little comprehension about the plan implemented ${ }^{(19)}$. Health workers must be aware that the absence of clear and precise information, as well as the existence of doubts, puts the health of the elder at risk, since it increases the odds of failure in home treatment due to the lack of knowledge.

Factors such as cognitive deficit, precarious general state, and low adherence to the therapy proposed were pointed out by the nurses as negative to the implementation of transition care, justifying the importance of support from relatives/caregivers in this process. However, these statements lead one to ponder whether said difficulties could be overcome if they were more closely monitored during hospitalization ${ }^{(20)}$.

Elders are more vulnerable and susceptible to damage during hospitalization due to the changes provoked by senescence, which impair homeostatic balance in situations of stress, leading to longer hospitalization times, inactivity, and mortality, when compared to young adults ${ }^{(21-22)}$. Furthermore, since most of them have multiple comorbidities, they have a higher risk of discontinuing their treatment in the transition period, due to factors such as: level of debility and low cognitive level, absence of a relative/caregiver, polypharmacy, and lack of understanding of the guidance with regard to home care - all of this can, in addition to increasing the odds of readmission, provoke adverse events and even death ${ }^{(15)}$. This is why they and their relatives/caregivers must be guided about the transition during their entire hospitalization.

The nurses interviewed recognized the importance of the guidance to more than just treating the coronary disease. However, in spite of this care, it can be noted that their focus is still on accordance with the biomedical model, permeated by prejudice, stereotypes, and labels socially attributed to elders, as indicated by some lines.

To this end, the information offered by the nurses seem to aim to transform an object, not a subject that can know. This attitude can be observed through lines and practices that transmit a strictly technical-scientific knowledge, "capable of saying the truth about how the other functions, but incapable of embracing that which the other brings"(23), not considering the project of life and the happiness of these people.

During the implementation of transition care, nurses must also adapt their guidance to the degree of dependence and functionality of the elder, associating their cardiological knowledge to gerontologic principles, to respect the choices and principles of those involved ${ }^{(17)}$. This is why it is also important for the elder to actively participate in their own self-care process, so planning can be carried out together.

A factor that negatively influences that hospital-home transition process, according to the lines, is the low adherence to the treatment, whether it is a drug treatment or not. The CAD treatment generally demands profound changes in the life of the elder. The insertion of new medication requires guidance about their risks and interactions, both for the elder and for relatives/caregivers. Furthermore, one must adopt healthy eating habits, the practice of physical activity, and a rigorous control of factors that aggravate the disease, such as arterial hypertension and diabetes ${ }^{(24)}$.

A home inquiry carried out in Brazil found that the factors that are most associated to the low adherence among elders were: age; not having health insurance; having to buy the medication; having three or more morbidities; being instrumentally incapable for daily life; and polypharmacy ${ }^{(25)}$. As a result, when elders and their relatives/caregivers are not well guided and involved in the therapeutic plan, home care after hospital discharger can be below the desired levels.

The absence of instruments that allow for an evaluation of the transitional care implemented when the user is hospitalized hinders the development of this care by the hospital post-discharge service. This situation, as indicated by the participants, makes it impossible to evaluate the patterns of response of these people, inhibiting: the identification of potential errors in the care; the implementation of new strategies; a critical analysis of the transitional care which is being practiced.

The statements of the participants also made it possible to find that there is no communication between the different health levels, not even within the multiprofessional team of the institution. When the elders are discharged, not only they received no previous preparation, they are also at risk of staying home alone, with no follow up from the post-discharge hospital service nor referral to other health services, except when they come back to the outpatient clinics for medical check-ups. Therefore, readmissions are used by the nurses as the final parameter of the preparation for discharge.

Studies have shown well-implemented models of transition care, in which post-discharge follow up takes place through remote monitoring, telephone calls or previously scheduled home visits, for one to three months after the user left the hospital. This follow up makes it possible for professionals to evaluate both the evolution of the patient, in their process of adapting to the new situation, and the transition care offered during hospitalization ${ }^{(2,26)}$.

A randomized clinical trial divided with 140 elders after acute myocardial infarctions in two groups (control and intervention), and found that the intervention group, which received telephone follow up about the treatment of the disease from health workers for 12 weeks after a hospital discharge related to the ischemic event, showed a better adherence to the drug therapy and to the healthy lifestyle, with lower rates of adverse effects and readmissions. All variables compared were statistically significant ${ }^{(27)}$.

Communication between the different health levels must be a component of transition care. That is why it is important to get to know the context of life of the person, and to guarantee their follow up, if possible, in health services that are close to their 
homes ${ }^{(28)}$, to adapt the planning of transition care to the reality of each person, avoiding difficulties in the adherence and leading to a satisfactory in-home adaptation.

For the transition process to be successful, transition care must be planned collectively and holistically, involving both the hospital and the home, through Primary Health Care services, articulated with the Health Care Network. Doing so, one can avoid adverse effects, such as medication and diagnostic errors, post-operative infections, and confusion states in elders, especially among those who already have some degree of dependence ${ }^{(16)}$.

\section{Study limitations}

The results of this research should be interpreted considering two limitations. The first is related to the small number of participants, which may not reflect the reality of transitional care in larger groups of nurses. The second limitation is associated to the fact that the study was carried out in a single hospital institution, which may generate changes in the planning and implementation of the transition care due to the rules and to the institutional dynamic, making it impossible to generalize results.

\section{Contributions to the fields of Nursing, Health or Public Policy}

The study contributes to foment discussions and build strategies to implement a holistic transitional care, in which nurses seek the necessary improvement to their practices, their service, and a to the profile of care. It is clear that a broad-scope transition care must be adopted, which includes the period of change experienced by patients and their families, to guarantee that they will have mastery over the needs of their new health conditions.

\section{FINAL CONSIDERATIONS}

This work suggests that the planning and implementation of the transition care practiced by nurses in elders with CAD is incomplete, restricted to guidance provided in the day of the discharge of the user, in a single moment, with no follow up of the learning or any guarantee that the information was understood. Furthermore, the discharge report is a support instrument used by the nurses, to which patients and their relatives/caregivers can resort after discharge.

The involvement of relatives/caregivers was found to be a positive factor in transition care by the nurses, and they recognize that factors such as fragility, cognitive deficits, and low adherence have a negative influence over the success of the transition care. They also do not evaluate the response of the patient with regard to the care implemented, and their parameter for it is the hospital readmission.

Judging by the results, there should be more discussions about the concept of transition care in the health units, which is broad and should start early, with the support of an articulated network.

\section{REFERENCES}

1. Hwang U, Dresden SM, Rosenberg MS, Garrido MM, Loo G, Sze J, et al. Geriatric emergency department innovations: transitional care nurses and hospital use. J Am Geriatr Soc. 2018;66(3):459-66. https://doi.org/10.1111/jgs.15235

2. Finlayson K, Chang AM, Courtney MD, Edwards HE, Parker AW, Hamilton K, et al. Transitional care interventions reduce unplanned hospital readmissions in high-risk older adults. BMC Health Serv Res. 2018;18(1):956. https://doi.org/10.1186/s12913-018-3771-9

3. Meleis Al. Transitions Theory: middle-range and situation-specific theories in nursing research and practice. New York: Springer Publishing Company; 2010. 664p.

4. Costa LGF. Visitando a teoria das transições de Afaf Meleis como suporte teórico para o cuidado de enfermagem. Enferm Brasil. 2016;15(3):137-45. https://doi.org/10.33233/eb.v15i3.181

5. Ivers NM, Schwalm JD, Bouck Z, McCready T, Taljaard M, Grace SL, et al. Interventions supporting long term adherence and decreasing cardiovascular events after myocardial infarction (ISLAND): pragmatic randomised controlled trial. BMJ. 2020;369. https://doi.org/10.1136/ bmj.m1731

6. Ministério da Saúde (BR). Departamento de Informática do SUS - DATASUS. Internações por faixa etária causadas por infarto agudo do miocárdio no Brasil [Internet]. Brasil: Ministério da Saúde. 2020 [cited 2020 Jun 15]. Available from: http://www2.datasus.gov.br/DATASUS/ index.php?area $=01$

7. Giannopoulos G, Karageorgiou S, Vrachatis D, Kousta M, Tsoukala S, Letsas K, et al. Usefulness of a structured adult education program in modifying markers of cardiovascular risk after acute myocardial infarction. Am J Cardiol. 2020;125(6):845-50. https://doi.org/10.1016/j. amjcard.2019.12.033

8. Vieira MB, Souza WS, Cavalcante PF, Carvalho IGM, Almeida RJ. [Men's perception after acute myocardial infarction]. Rev Bras Promoç Saúde. 2017;30(3):1-9. https://doi.org/10.5020/18061230.2017.5833 Portuguese.

9. Acosta A, Câmara C, Weber L, Fontenele R. [Nurse's activities in care transition: realities and challenges]. Rev Enferm UFPE. 2018;12(12):31907. https://doi.org/10.5205/1981-8963-v12i12a231432p3190-3197-2018 Portuguese.

10. Cacchione PZ. Innovative care models across settings: providing nursing care to older adults. Geriatric Nursing. 2020;41(1):16-20. https://doi. org/10.1016/j.gerinurse.2020.01.011

11. Ministério da Saúde (BR). Conselho Nacional de Saúde. Resolução no 466, de 12 de dezembro de 2012. Regulamenta a pesquisa envolvendo seres humanos. Diário Oficial da União: República Federativa do Brasil [Internet]. 2012 Jun 13[cited 2020 Jun 02]; Seção 1:59 (col.3).

Available from: http://bvsms.saude.gov.br/bvs/saudelegis/cns/2013/res0466_12_12_2012.html 
12. Tong A, Sainsbury P, Craig J. Consolidated criteria for reporting qualitative research (COREQ): a 32-item checklist for interviews and focus groups. Int J Qual Health Care. 2007;19(6):349-57. https://doi.org/10.1093/intqhc/mzm042

13. Mendes RM, Miskulin RGS. [Content analysis as a methodology]. Cad Pesqui. 2017;47(165):1044-66. https://doi.org/10.1590/198053143988 Portuguese.

14. Bardin L. Análise de Conteúdo. Edições 70; 2016. 280p.

15. Menezes TMO, Oliveira ALB, Santos LB, Freitas RA, Pedreira LC, Veras SMCB. [Hospital transition care for the elderly: an integrative review]. Rev Bras Enferm. 2019;72(Suppl2):294-301. https://doi.org/10.1590/0034-7167-2018-0286 Portuguese.

16. Weber LAF, Lima MADS, Acosta AM. Quality of care transition and its association with hospital readmission. Aquichan. $2019 ; 19(4):$ e1945. https://doi.org/10.5294/aqui.2019.19.4.5

17. Pereira FGF, Pinheiro SJ, Caetano JA, Ataíde MBC. [Characteristics of nursing students' health education practices]. Cogitare Enferm. 2016;21(2):1-6. https://doi.org/10.5380/ce.v21i2.44209 Portuguese.

18. Nunes SFL, Alvarez AM, Costa MFBNA, Valcarenghi RV. Determining factors in the situational transition of family members who care of elderly people with Parkinson's disease. Texto Contexto Enferm. 2019;28:e20170438. https://doi.org/10.1590/1980-265x-tce-2017-0438

19. Jeffs L, Saragosa M, Law M, Kuluski K, Espin S, Merkley J, et al. Elucidating the information exchange during interfacility care transitions: insights from a qualitative study. BMJ Open. 2017;7:e015400. https://doi.org/10.1136/bmjopen-2016-015400

20. Lima MADS, Magalhães AMM, Oelke ND, Marques GQ, Lorenzini E, Weber LAF, et al. [Care transition strategies in Latin American countries: an integrative review]. Rev Gaúcha Enferm. 2018;39:e20180119. https://doi.org/10.1590/1983-1447.2018.20180119 Portuguese.

21. Freitas FAS, Santos ESS, Pereira LSM, Lustosa LP. [Physical vulnerability of older adults in hospital discharge]. Fisioter Pesqui. 2017;24(3):2538. https://doi.org/10.1590/1809-2950/16205224032017 Portuguese.

22. Hardicre NK, Birks Y, Murray J, Sheard L, Hughes L, Heyhoe J, et al. Partners at care transitions (PACT)-exploring older peoples' experiences of transitioning from hospital to home in the UK: protocol for an observation and interview study of older people and their families to understand patient experience and involvement in care at transitions. BMJ Open. 2017;7(11):1-8. https://doi.org/10.1136/ bmjopen-2017-018054

23. Andrade EO, Givigi LRP, Abrahão AL. A ética do cuidado de si como criação de possíveis no trabalho em Saúde. Interface Comun Saúde Educ. 2018;22(64):67-76. https://doi.org/10.1590/1807-57622016.0643

24. Bonow B,囚 Libby L, Mann DL, $\bigotimes$ Zipes D. Braunwald: Tratado Doenças Cardiovasculares. Elsevier, 2017. 2200p.

25. Tavares NUL, Bertoldi AD, Mengue SS, Arrais PSD, Luiza VL, Oliveira MA, et al. [Factors associated with low adherence to medicine treatment for chronic diseases in Brazil]. Rev Saúde Pública. 2016;50(suppl.2):1s-11s. https://doi.org/10.1590/S1518-8787.2016050006150 Portuguese.

26. Buurman BM, Parlevliet JL, Allore HG, Blok W, van Deelen BA, van Charante EPM, et al. Comprehensive geriatric assessment and transitional care in acutely hospitalized patients: the transitional care bridge randomized clinical trial. JAMA Intern Med. 2016;176(3):302-9. https://doi. org/10.1001/jamainternmed.2015.8042

27. Wu Q, Zhang D, Zhao Q, Liu L, He Z, Chen Y, et al. Effects of transitional health management on adherence and prognosis in elderly patients with acute myocardial infarction in percutaneous coronary intervention: a cluster randomized controlled trial. PLoS One. 2019;14(5):e0217535. https://doi.org/10.1371/journal.pone.0217535

28. Paniagua DV, Ribeiro MPH, Correia AM, Cunha CRF, Baixinho CL, Ferreira Ó. [Project K: Training for hospital-community safe transition]. Rev Bras Enferm. 2018;71(Suppl-5):2264-71. https://doi.org/10.1590/0034-7167-2018-0190 